\title{
The Emerging Energy Internet: Architecture, Benefits, Challenges, and Future Prospects
}

\author{
S. M. Suhail Hussain ${ }^{1, *(\mathbb{C}}$, Furquan Nadeem ${ }^{2}{ }^{\mathbb{C}}$, Mohd Asim Aftab $^{3}$, Ikbal Ali $^{3}$ and \\ Taha Selim Ustun ${ }^{1}$ \\ 1 Fukushima Renewable Energy Institute, AIST (FREA), Koriyama 963-0215, Japan; selim.ustun@aist.go.jp \\ 2 Department of Electrical Engineering, National Institute of Technology Silchar, Cachar 788010, India; \\ scholar.furquan@gmail.com \\ 3 Department of Electrical Engineering, Jamia Millia Islamia (a Central University), Jamia Nagar, \\ New Delhi 110025, India; mohdasimaftab4@gmail.com (M.A.A.); iali1@jmi.ac.in (I.A.) \\ * Correspondence: suhail.hussain@aist.go.jp; Tel.: +81-704-386-4127
}

Received: 29 August 2019; Accepted: 14 September 2019; Published: 15 September 2019

\begin{abstract}
Energy Internet is a concept proposed to harness, control, and manage energy resources effectively, with the help of information and communication technology. It improves a reliability of the system, and provides an increased utilization of energy resources by integrating the smart grid with the Internet. A scalable and reliable information and communication architecture is a crucial factor for both the operation and management of the energy Internet. The routing or managing of electrical energy is performed through an energy router (ER), synonymous with a communication router, which routes data packets instead of energy packets. In this paper, a holistic review of the energy Internet evolution in terms of the architecture, types of ERs, and the benefits and challenges of its implementation is presented. An exhaustive summary of the designs and architectures of the different types of ERs is also presented in this paper. The benefits of the energy Internet, along with the challenges of its implementation on a large-scale distributed architecture with the inclusion of renewable energy resources, is discussed. Finally, future prospects for the energy Internet for achieving guaranteed reliability and security is presented.
\end{abstract}

Keywords: energy internet; smart grid; information and communication technology; distributed energy resources; energy router

\section{Introduction}

Overdependence on fossil fuels, such as coal, natural gas, and oil, for energy needs in the current energy consumption scenario leads to two major issues - the fast exhaustion of conventional energy resources leading to an energy crunch, and global warming, due to increased greenhouse gas emissions. To address these issues, harnessing energy from non-conventional energy resources, such as solar, wind, biomass, ocean, and geothermal, and the development of an efficient and reliable energy utilization regime are required. These non-conventional energy resources are usually distributed in geographic areas, and demand energy utilization from distributed energy resources (DERs) [1]. This has led to a paradigm shift from the traditional centralized power generation to distributed power generation. These distributed generation plants are governed by centralized players that manage and control them through advanced communication technology. This has led to the emergence of the smart grid (SG) $[2,3]$. SG is a unique and advanced concept combining interconnected power systems, intelligent networks, and smart monitoring, which greatly improves the utilization of energy resources [4].

The centralized control scheme in SG is gradually transforming to a hierarchical distributed control, with the aid of advanced information and communication technologies (ICT) [5-7]. This 
contributes to the higher participation of small- and micro-level prosumers in the energy market, and the development of a distributed and active energy production regime with bidirectional power transmission. The distributed, collaborative Internet will converge with the energies that are also distributed and collaborative. Today, we have millions of potential micro power plants (MPP) with clean and renewable non-conventional energy sources. Each consumer can produce their electricity from the installed MPPs and accomplish their energy needs. If excess energy is produced, it can be sold to the grid, and the consumer gets paid for it in peak load periods. In case there is a shortage of supply, the energy is purchased from the grid in order to manage the demand supply. These prosumers act as distributed renewable energy resources (DRERs) during grid energy deficient periods, and as distributed energy storage devices (DESDs) during grid energy excess periods, and thus provide better efficiency and grid stability [8-10].

In order to effectively manage the operation of DRERs and DESDs, and to lower the energy production, transportation, and storage costs, greater emphasis is laid on the integration of information technology with the energy sector [11-13]. It will be a complete paradigm shift in the energy system direction of today's world, to deploy a ubiquitous energy control system. This has evolved the concept of the management of energy, and is known as the energy Internet (EI). EI is a combination of the energy sector and Internet of things (IoT), as described by its originator Jeremy Rifkin in his book "Third Industrial Revolution" [14]. EI is also known as "Enernet", which is an Internet of energy (IOE) [15]. EI is an integration of DRERs, DESDs, real-time energy monitoring, information sharing, real-time pricing, and energy transactions. EI aims to transform energy production, storage, and transport into an Internet-enabled form. EI aims to realize a scenario where every household can be involved in an energy transaction [16]. The EI revolution will present quantum leaps in terms of energy security, and will aid to develop a cleaner, healthier, and safer environment for energy exchange [17].

Research has shown that the concept of EI has surpassed the geographical barriers of energy transmission, because of the low-cost of information transmission [18]. In the literature [19,20], a hierarchical energy management system to address economically- and environmentally-viable operations of micro EI by handling the power flow exchanged between the micro EI and the host grid is proposed. As the concept of EI involves energy transactions, a business perspective of EI involving multiple energy transaction stages has been discussed [16]. Different communication technologies along with standard communication protocols for EI is addressed in the literature [21]. Also, the security challenges involved with EI communication technology are discussed by the authors of [18]. In the literature [22], an architecture of a multilevel internet-aided microgrid system for interfacing distributed renewable energy resources with EI in a flexible manner is proposed. A solution for the peak load shifting problem and demand-side management with energy trading among the end-users of EI is given by the authors of [23].

Based on previous research works and the growing attention in this area, a thorough review for EI is required. This paper presents a review on EI, typically focusing on the different architectures of EI, as well as the models of energy routers (ER) employed for EI operations. Also, the challenges faced in EI implementation are discussed, and future prospects for EI are presented.

The organization of this paper is as follows. Section 2 describes the concept and architecture of the energy Internet. The types of ERs employed in EI operation are explained in Section 3. The role of EI in the smart grid is discussed in Section 4. Section 5 presents the benefits of EI and the challenges in EI implementation. Section 6 provides future prospects for EI. Finally, Section 7 presents the conclusion.

\section{Energy Internet: Concept and Architecture}

EI can be defined as a dynamic and distributed network, which integrates various sources of energy into an efficient and multi-participant grid in order to build a green, clean, and flexible energy network [22,24]. EI can also be defined as the integration of the existing power system with distributed energy resources for energy delivery and management. EI can serve as the foundation of smart cities and smart buildings [25]. 
EI can be envisioned as an internetwork of distributed energy resources (i.e., DRERs and DESDs) combined with legacy power systems, and supporting communication through the Internet, as shown in Figure 1. The concept of EI is the next level of smart grids. EI is based on distributed energy resources that can act as prosumers. EI contains controllable loads powered by IOT, and operates them in different energy modes for optimizing energy flow. In the literature [18,22], the authors proposed different architectures of EI. Tsoukalas [26] discussed the architecture of EI, with a focus on the interactions among the agents (generation and transmission) in an economic prospective. However, their model lacks the integration of DRERs, the flexibility of supply (AC/DC) and communication between the end users, and utility. Furthermore, nowadays, consumers can have a variety of loads, such as battery charging for electric vehicles, or in the future, there may be a small DC nano-grid for some specific purpose [27]. Hence, the flexibility of the AC/DC supply is an important factor for EI architecture. Huang et al. [22] focused extensively on the integration of diverse DRERs and DESDs in Future Renewable Electric Energy Delivery and Management (FREEDM) architecture, which is mainly based on the operation of the new generation of solid state transformers (SSTs). Among the different architectures, the FREEDM architecture of EI is the most commonly employed. This is due to the fact that it considers a flexible and distributed integration and management of DRERs and DESDs with the existing power system, making a stable and reliable microgrid structure. In order to achieve the realization of the EI architecture, this section covers the key components of the FREEDM architecture in detail.

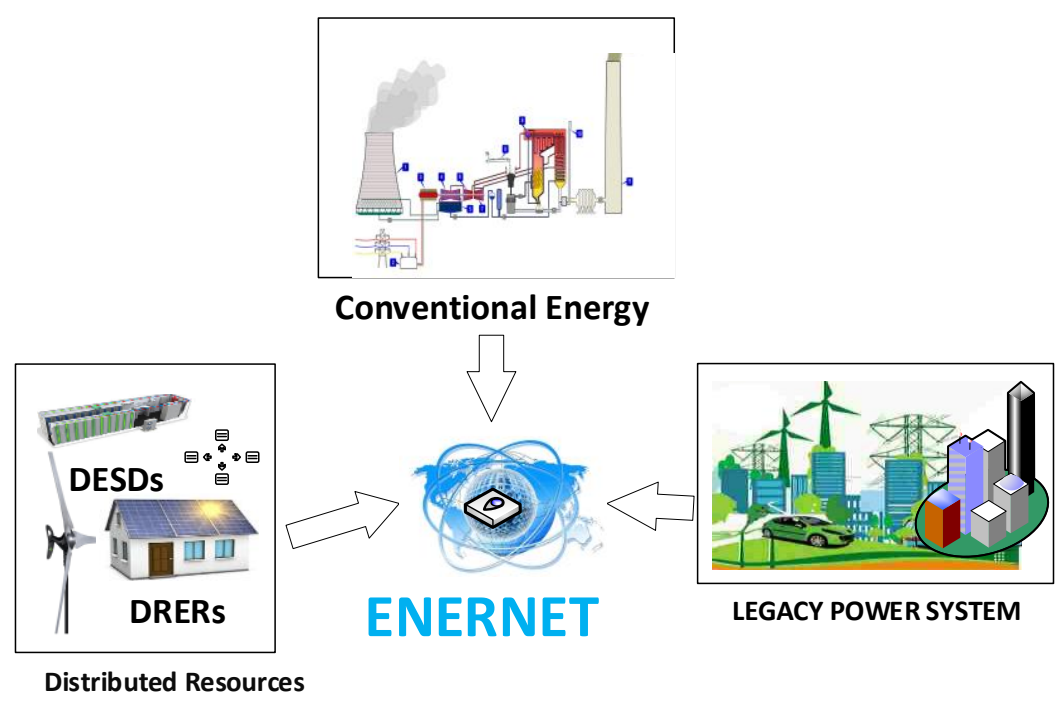

Figure 1. Vision of the energy Internet.

\subsection{FREEDM Architecture with Multiple Levels}

The FREEDM architecture is a vision that integrates renewable energy resources into the grid, and the residential users manage their energy needs through a standardized plug-and-play interface [19]. It combines a wide scale of DRERs and DESDs into the smart grid powered with the Internet, having real-time communication between the power devices [28]. It can aid in developing dynamic scheduling and management facilities for an efficient and pollution-free green industry and society [29]. The FREEDM structure has interfaces for both industrial and domestic consumers, and has a wide scope of flexibility for constantly the changing behavior of DRERs, enabling a decentralized energy market with a two-way energy flow of active end users. This allows customers to sell the excess power back to the grid at a real-time price, which is obtained through an intelligent energy management software that analyses the pricing information based on the real-time demand and generation.

The FREEDM system architecture coexists with the legacy of the AC system power infrastructure, with only minimal issues related to the raising and lowering of circuit voltages. A utility company or 
subdivision association will be the owner of the local FREEDM structure, and customers will have their own DRERs and DESDs in addition to their loads [30]. This will maintain a two-way energy exchange.

In order to provide an uninterrupted power supply in the fault conditions, an effective isolation and reconfiguration ability is provided to the power line by an intelligent fault isolation management (IFM) device in the FREEDM structure [31]. The fault isolation device (FIDs) will communicate with IFMs, as well as other FIDs, through reliable and secure communication. The functions of FID include isolating the fault line and reclosing the section when the fault is cleared. Hence, the functions of the sectionalizer and recloser are achieved by IFM [32].

The operation of the FREEDM structure is distributed into five levels. The levels of operation in the FREEDM design are shown in Figure 2. The description of the different levels of operation is as follows.

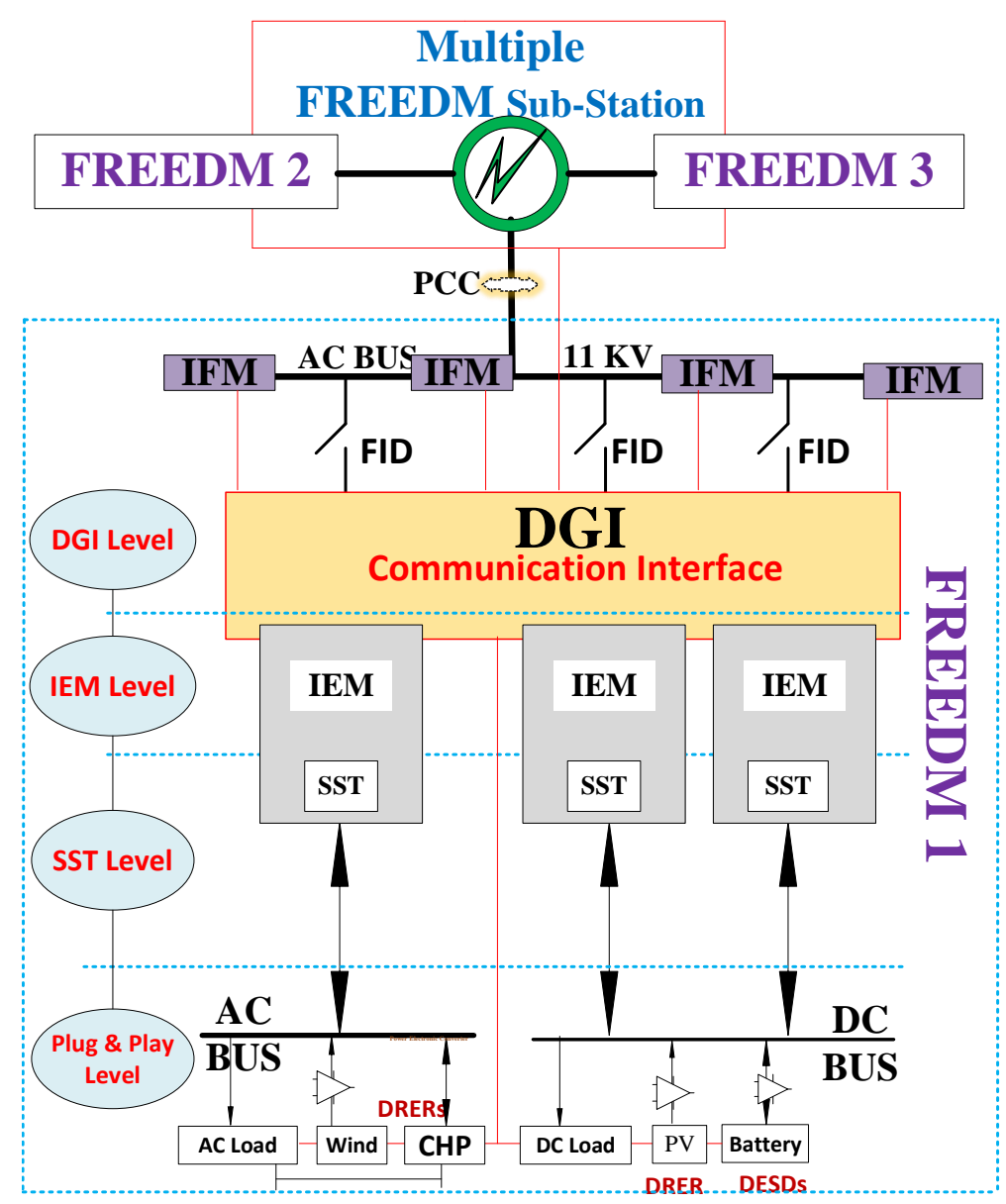

Figure 2. Levels of operation in Future Renewable Electric Energy Delivery and Management (FREEDM) design in the energy internet (EI) .

\subsubsection{Plug-And-Play (PnP) Level}

The PnP level of operation integrates the power devices, especially DRERs and DESDs, anytime and anywhere, with the existing smart grid [33]. It helps with the easy and instant recognition of power devices, as soon as they get connected. The PnP infrastructure connects all of the devices of FREEDM to the EI, using wired or wireless protocols [34], such as fiber optics, power line communication (PLC) [35], ZigBee [36], worldwide interoperability for microwave access (WiMAX) [37], cognitive radio (CR) [38], long-term evolution (LTE) network [39], and cellular communications [40]. 


\subsubsection{Solid State Transformer (SST) Level}

The SST level contains a power electronic transformer, which manages the interface between the customer loads, DRERs, and DESDs [41]. The SST is different from the legacy distribution transformers because of the involvement of power electronic converters, which offers typical functionalities, such as multilevel power conversions (high voltage AC/DC power conversion for DC buses, DC/DC conversion for high-frequency DC regulated buses, and DC/AC conversion stages for low-voltage regulated AC buses), and makes it a three-level power exchange [42]. The size of the SST transformer is reduced considerably compared with that of the conventional transformer because of the employment of high-frequency silicon carbide ( $\mathrm{SiC}$ ) insulated gate bipolar transistor (IGBT) technology, which makes it lighter and more compact $[43,44]$. SST will act as a smart and intelligent plug-and-play interface device that supports different interfaces (AC/DC) via AC and DC ports.

A block diagram of SST is shown in Figure 3. It interfaces different levels of DC bus outputs and aids in voltage sag restoration, fault current limiting, power factor correction, and reactive power flow balancing [45]. There can be multiple SSTs under one ER, which acts in coordination.

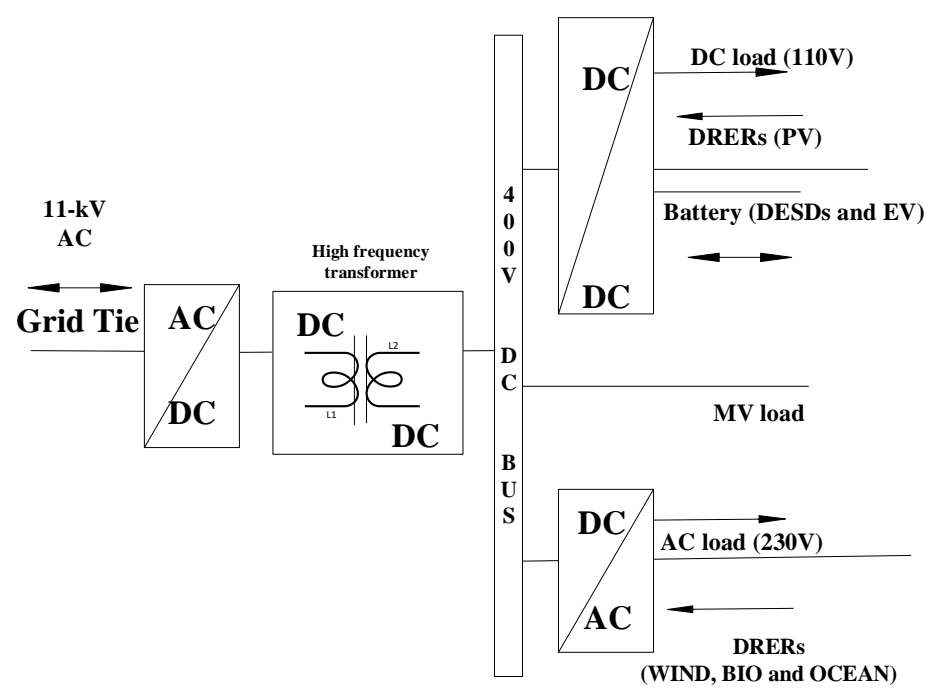

Figure 3. Block diagram of a distribution-solid state transformer (SST).

\subsubsection{Intelligent Energy Management (IEM) Level}

The IEM level coordinates the SST and PnP level in order to manage DRERs, DESDs, and loads effectively. The typical functions of the IEM level include control commands to the SST, the management of ER, control of DESDs for charge/discharge, and so on [46].

IEM also communicates with the intelligent fault management (IFM) system of the respected local area for fault isolation. The revenue metering and instrumentation systems are also managed by IEM for its participation in the demand side management. According to varying information about load-demand and network topology, the effective correctness of the unit commitment and tariff scheduling is updated by IEM in coordination with higher levels of the FREEDM system.

\subsubsection{Distributed Grid Intelligence (DGI) Level}

DGI is the core level of the FREEDM design and it governs the energy needs of local ER with the coordination of other FREEDM structures of the grid [47]. At the DGI level, energy management schemes are applied after the identification of loads and DESDs, and generation through DRERs. DGI will act as a common platform for all IEM and IFM nodes, through which a power balance is achieved in a time-sensitive manner. A multi-level ER communication is possible with a DGI platform [48]. For optimal load scheduling and grid stability management, DGI plays a key role in the shedding of unnecessary loads, turning on/off back-up generators, and discharging DESDs to serve the critical loads. 
The DGI will coordinate with the IEM in order to change the load consumption, based on the different operating modes of the grid. If the disturbance of a grid (e.g., approaching a storm or peak-load hours) is anticipated, then the charging of DESDs is maximized and the power availability for low-priority loads is minimized. According to the alertness level by DGI, the excess power can also be shared with the other users of the FREEDM structure in the grid. In order to maximize effective power marketing, DGI will consider the business policies along with the operational requirements in decision making. With the DGI operating system, the number of IEM and IFM nodes can be increased or decreased as per the requirement, without any major change in the system. The DGI operating system is dumped in each node of IEM and IFM, making it a flat and distributed controlling architecture that is different from the centralized supervisory control and data acquisition (SCADA) conventional system. The coordination between multiple levels of control in different time scales is the main challenge for DGI software. Furthermore, DGI software should be able to tackle the challenges of interoperability when operating with devices manufactured by different vendors. This challenge can be addressed by adopting interoperable standards, like IEC 61850, DNP3, or openADR for DGI communication.

\subsubsection{Multiple FREEDM Grid Level}

There needs to be proper communication and energy interchange between the multiple-microgrids and the main grid (MG). In order to achieve this at a substation-ER level, we implemented a consensus algorithm [49]. The common goals of all of the microgrids are placed at first priority in the consensus algorithm. The tertiary control and secondary control at a distribution and microgrid level, respectively, are managed at this stage. A group of individual physical systems (ERs) are made the agent. Each agent (ER) has a local controller (i.e., IEM) and consensus manager (DGI). The local controller will continuously update its status to the consensus manager, and after calculating the consensus result based on communication with neighboring agents, the manager will pass the decision to the local controller. The IEM will modify and adjust its actions iteratively based on the decisions of DGI , and update its new state to the consensus manager.

\section{Types of Energy Routers}

The core and heart of the EI is ER. ER controls and manages the energy generation, distribution, storage, and dynamic pricing [50]. The prominent features of ER are optimal energy management, providing bidirectional power flow among different terminals of the FREEDM structure, and the isolation of fault lines with minimum disturbance. The effective coordination of basic units of ER results in an efficient and modular design of EI. To achieve these intelligent features of ER equipped with DRERs and DESDs, different conceptual designs are proposed, which are discussed in subsequent paragraph.

The research on ER architecture and design modeling leads to three different types of designs, which are explained below.

\subsection{The Energy Hub Model}

This model consists of multiple energy producers and consumers interconnected by energy hubs or energy interconnectors [50]. The hub interface works directly or via the conversion of energy, with producers, consumers, storage devices, and transmission equipment, to supply the consumer needs. It is aided with cogeneration and transmission, in order to get the maximum efficiency out of the hub system. For integrated transmission among several energy carriers, each hub is powered with fuel cells, electrolyzers, thermoelectric converters, power electronic converters, heat pumps and so on. The hub has multiple types of energy inputs, and on the output side, the energy source can be CHP or any other, depending on the demand of the end consumer.

In Figure 4, if the energy hub is transmitting electricity and gas to the consumer, then the heat losses inside the system are transmitted to gas, which can be utilized further to supply heat to the output side, and as a result, the efficiency is greatly improved [51]. However, this approach lacks proper technical development, and the interconnections of various energy equipment's are not considered. 


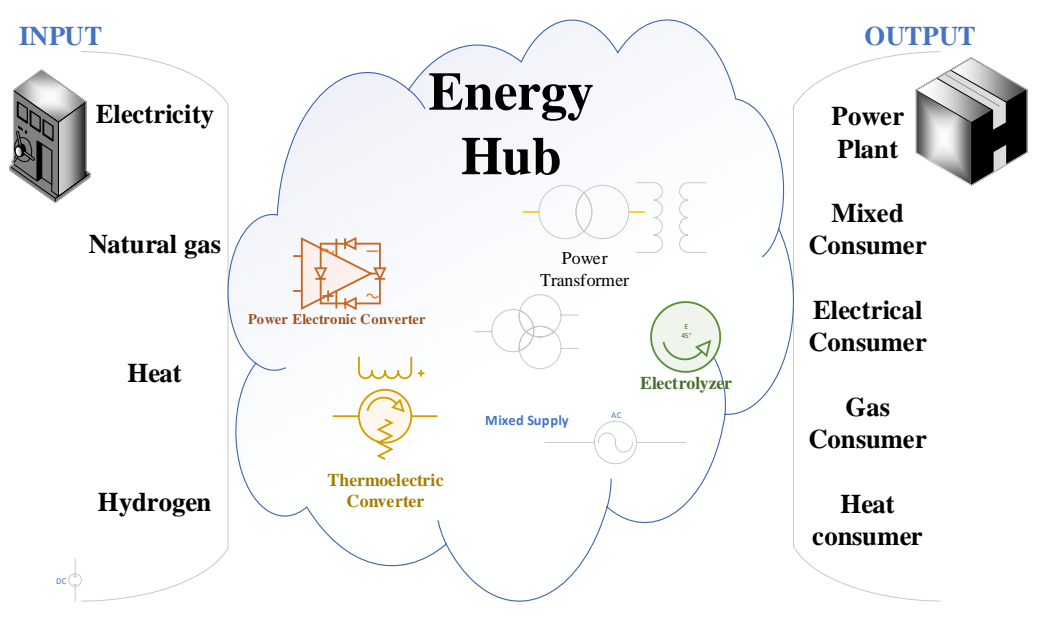

Figure 4. Energy hub model.

\subsection{SST-Based ER Model}

The SST-based ER model is a common model used in various EI models. This model is a core component of EI in the FREEDM architecture presented by the authors of [22], and is discussed in detail in the previous section. Unlike the energy hub, the SST-based ER considers different domains of the grid (i.e., generation, transmission, distribution, operation, servicing, and trading) along with user level functions, such as the distributed load attachment, detachment, status update, and service isolation, as shown in Figure 5. However, as compared to the energy hub model, SST-based ER supports only electrical energy, whereas the former also supports other forms of energy such as heat.

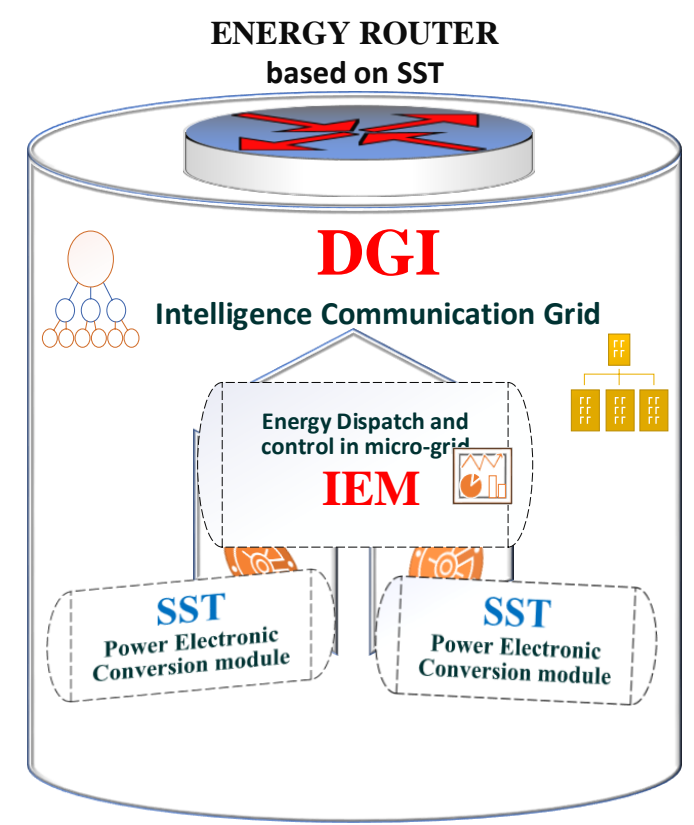

Figure 5. Organization of an energy router (ER) in a FREEDM structure. DGI—distributed grid intelligence.

\subsection{Multiport Converter (MPC) and Power Line Communication (PLC)-Based ER Model}

In order to achieve the high degree of reuse and integration for SST-based ER, H. Guo [52] presented multiport converter- (MPC) and PLC-based ER. The MPC- and PLC-based ER are considered as improved versions of the SST-based ER. In MPC-based ER, all types of distributed energy devices are connected and controlled with bidirectional power electronic converters, as shown in Figure 6. The communication and energy transmission layers run in parallel at each level. At the microgrid 
control center, the functions of energy control and information management are performed. All of the DRERs and DESDs, along with the loads, are connected with the local DC bus, which is managed by a bidirectional multiport buck-boost converter, capable of operating in a grid tie or islanded mode [53].

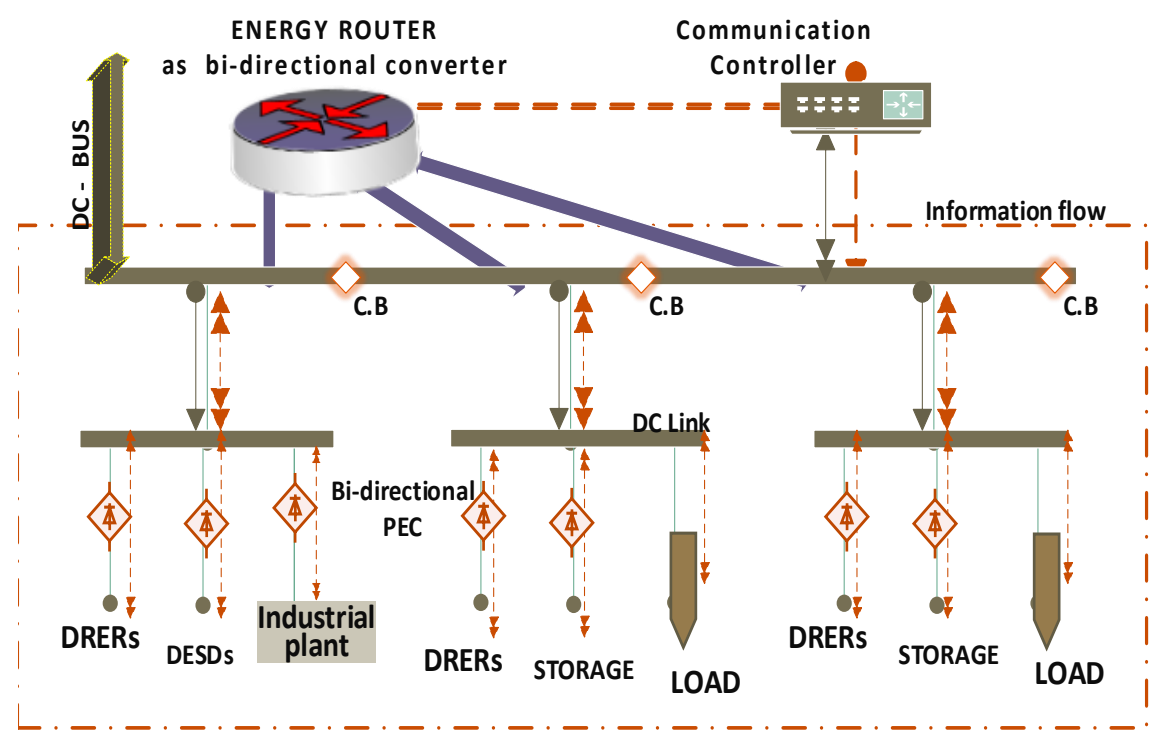

Figure 6. Multiport converter (MPC)-based E-router model.

In PLC-based ER, the power line communication technique is used for information management and power transmission. Because of the employment of the PLC scheme, PLC-based ER is compact in size, and saves additional communication network investment. It works on the wires of the existing widely distributed power network structure of the microgrid. However, the PLC technique has drawbacks, such as a loud noise, signal attenuation, constrained bandwidth, and low transmission rate. Furthermore, the PLC technique has a major drawback of no backups for communication. When the power line is damaged or broken, the PLC communication is lost. In the literature [32], the amplify and forward-based relay-aided (AF-based RA) PLC technique is proposed in order to overcome the technological challenges of a low transmission rate in the distribution feeder and substation feeder. The main idea of the PLC-based ER is to send the power into the form of energy packets, similar to the information packets of Internet technology [54]. All of the energy outputs are configured as power packets quantized with the address information of the source and destination device. These are then multiplexed over a transmission line with a time-division multiplexing (TDM) technique. At the receiving end of the transmission line, the E-router will decouple the energy packets and route them to the load destination. A representation of the PLC-based ER is shown in Figure 7. The DESDs play a major role in PLC-based router design, with the source-load balancing by buffering the intermittent energy packets generated by the intermittent nature of DRERs. The amount of supplied power is regulated by changing the length of the packet or by modulation of the power waveform.

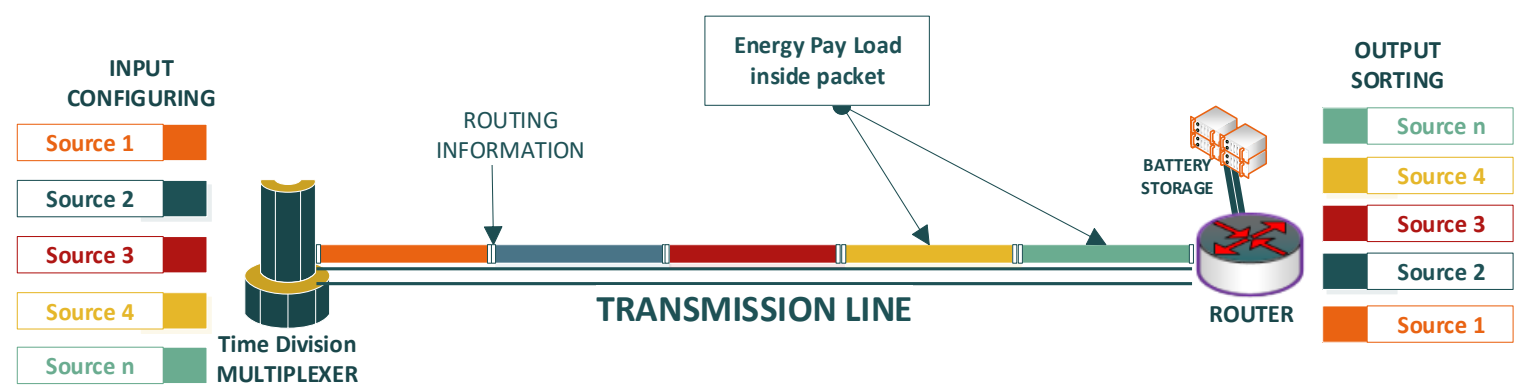

Figure 7. Power line communication (PLC)-based E-router control model. 
Based on different features, a comparative analysis among different designs for ER is shown in Table 1.

Table 1. Comparison between multiple designs of ER. DRER—distributed renewable energy resources; DESD— distributed energy storage devices.

\begin{tabular}{|c|c|c|c|c|c|c|}
\hline $\begin{array}{l}\text { Design } \\
\text { Feature }\end{array}$ & Design Parameter & \multicolumn{5}{|c|}{ Supported Features } \\
\hline $\begin{array}{l}\text { Basic ER } \\
\text { design } \\
{[22,28]}\end{array}$ & $\begin{array}{l}\text { Acts as intelligent energy } \\
\text { node with three-layer } \\
\text { functions shared among SST, } \\
\text { IEM, and DGI. All DRERs } \\
\text { and DESDs are connected } \\
\text { directly with the ER having } \\
\text { Plug-n-Play interfacing. }\end{array}$ & Yes & Yes & Yes & Yes & Yes \\
\hline $\begin{array}{l}\text { Energy } \\
\text { hub-based } \\
\text { design } \\
{[51,55]}\end{array}$ & $\begin{array}{l}\text { Swiss Science team proposed } \\
\text { it as unit of energy generation, } \\
\text { conversion and storage. }\end{array}$ & Yes & No & No & Yes & Yes \\
\hline E-router [52] & $\begin{array}{l}\text { Designed for dispatch and } \\
\text { control of low voltage } \\
\text { equipment. }\end{array}$ & Yes & Yes & Yes & Yes & Yes \\
\hline
\end{tabular}

\section{Role of Energy Internet in Smart Grid}

The SG concept is naturally associated with a communication-based control on the production and utilization of electrical energy [57]. The smart grid provides social benefits such as a lower energy cost, reduced emissions, and more flexibility to accommodate new DRERs. These results can be achieved by the integration of different technologies, including ICT, which are necessary for making the energy demand and production more predictable and controllable. The information will be collected from smart meters, which are placed in residential homes, commercial buildings, and industries, through a communication media via, for example, WiFi, Zigbee, and SCADA systems [3]. With the employment of smart grid technology, power system automation can be achieved. The role of EI on various areas of the smart grid is discussed below.

\subsection{Energy Internet as a Smart Grid Enabler}

The vision of IOT is to connect anytime, anything, and anywhere to the global information network. The goal of the smart grid is to monitor and control the energy generating units by providing two-way communication, anyplace and anytime, between the grid and IEM system [58]. To communicate with large-scale remote areas, a wireless system is efficient. The integration of the vision of IOT and SG is enabled by EI. Sensing and measurement are the backbone of smart grid. Smart meters and advanced metering infrastructures (AMIs) will support, monitor, and control energy [59]. EI will ease the wide distributed area management for enabling smart grid services. Also, the recent advances in low-power integrated circuits and wireless communications, offers efficient, low cost, and low power consumption devices for use in remote sensing applications [60].

An EI system decentralizes the areas with large-scale distributed renewable generation, in order to balance the supply and demand, whereas a smart grid follows a localized approach. EI provides 
a bidirectional exchange of power supply between the power grid and customers through a single infrastructure based on ER. It offers a platform of intra energy exchange for multiple forms (thermal, chemical, and so on) for distributed energy sources [51]. As compared in Table 2, the SG objectives of integration, interoperability, and security can be achieved through the concept of EI.

Table 2. Comparative features between the smart grid and energy Internet.

\begin{tabular}{|c|c|c|}
\hline Parameter of Comparison & SG Communication [3] & EI Communication [21] \\
\hline Characteristics & Information transmission & Energy and information transmission \\
\hline Service objects & Multi-source heterogeneous data & $\begin{array}{l}\text { Multiple distributed renewable energy } \\
\text { and multi-source heterogeneous data }\end{array}$ \\
\hline \multirow{2}{*}{ Routing equipment } & Smart meters & ER \\
\hline & Grid interconnection & Grid interconnection \\
\hline \multirow{2}{*}{ Functionalities } & Data processing & Data, energy transmission, and processing \\
\hline & Grid management & Grid management \\
\hline Standards available & $\begin{array}{l}\text { International standards such as } \\
\text { IEC } 61850[61] \text { and DNP3 }\end{array}$ & Not yet available \\
\hline
\end{tabular}

\subsection{Energy Internet as a Peak Load Optimizer}

EI can manage the load demand effectively in a smart grid scenario. During the peak load when the energy demand exceeds the generation, the reliability of the power supply is hampered. The scheme applied to mitigate this issue is managing the economics of the grid, based on the formula of high consumption-high payment, and vice versa, during peak hours. Thus, the peak load shaving is achieved by shifting the utilization time of the energy without varying the overall energy consumption. A novel real-time pricing (RTP) model for electricity usage and scheduling is proposed in the literature [16]. It works on the application of smart meters to collect data and optimize energy production. In the direct load control (DLC) method [62], for dispatch and unit commitment coordination, EMS will end up with a load curtailment in the peak load hours, causing system disturbance and customer dissatisfaction. In the literature [63], an evaluation of the economic feasibility of the electrochemical storage systems in the peak load shaving applications, along with the sizing and operating strategy of the battery energy storage system (BESS or DESD) is presented. Although this strategy improves the conventional electrical grid, it does not consider the EI framework as its mathematical model, and lacks the involvement of renewable energy sources.

In the literature [23], an EI-based peak load shifting problem is addressed by trading energy among the end-users. The EI framework realizes the energy demand data through smart meters, and then sends this information to the control center, which distributes the energy to meet the user demands. The end-user can sell the energy from their own storage facility, such as EVs and DESDs, by just plugging the storage units into the grids. Applying real-time pricing will decrease the operating cost in this framework. The proposed model of optimal energy management system (EMS) in the literature [64] can be applied to any energy system characterized by multiple productions, storage systems, and distribution systems that have unique decision makers. The overall objective function of EMS here should be to minimize the sum of the net operating costs, as follows:

$$
\text { Min } \mathrm{C}_{\mathrm{TOT}}+\mathrm{Co}_{2} \mathrm{E}_{\mathrm{Co}_{2}}
$$

Here, $\mathrm{CO}_{2}$ is the parameter corresponding to the price of emission for one ton of coal, $E_{\mathrm{Co}_{2}}$ is the overall $\mathrm{Co}_{2}$ emissions, and $\mathrm{C}_{\mathrm{TOT}}$ is the overall operating cost given as follows:

$$
C_{T O T}=C_{B}+C_{k}+C_{R E S}+C_{\text {grid }}+B_{\text {grid }}
$$

In the above equation, the terms $C_{B}, C_{k}, C_{\text {grid }}, C_{R E S}$, and $B_{\text {grid }}$ represent the operating costs due to the boiler, microturbines, external grid charge, renewable energy sources, and financial benefits related to the electricity exchange with the grid, respectively. However, Equations (1) and (2) are based on 
the assumption that the energy usage cost of all of the end-users in a day, and the cost of generating (charging) the renewable energy are not considered in $C_{\text {grid }}$. In the literature [23], C. C. Lin extended this model with the consideration of the EI framework, and adopted the influence of RTP on the distribution of the electricity supply and demand. The objective function of this model is as follows:

$$
\text { minimize } C_{\text {grid }}+C_{m}+C_{R E S}-B_{\text {grid }}
$$

where $C_{\text {grid }}$ is the total grid energy usage cost of the all end-users, which is a function of RTP on an hourly basis and the grid energy used for charging.

$$
C_{\text {grid }}=\sum_{t=1}^{24} R T P_{i}(t) \cdot E_{L}^{i}(t)+\sum_{t=1}^{24} R T P_{i}(t) \cdot E_{E S, t}^{i} \cdot \delta_{\text {grid }, t}
$$

Here, $\operatorname{RTP}_{i}(t)$ represents the RTP at the $t$-th hour on day $i$; $E_{L}^{i}(t)$ is the amount of the gird energy used by the end-users at the $t$-th hour on day $i ; E_{E S, t}^{i}$ is the amount of the grid energy used by end-users to charge at the $t$-th hour on day $i ; \delta_{\text {grid, }}$ is a binary decision variable that decides whether end-users use the grid energy at the $t$-th hour to charge electricity (i.e., $\delta_{\text {grid, } t}=1$ represents power charging; $\delta_{\text {grid, } t}=0$ represents power discharging).

The energy generated by Wind and PV can be used by customers directly or else they can store it in the DESDs. The maintenance cost of energy storage facilities of all end-users is given by $C_{m}$, charging $\operatorname{cost} C_{R E S}$ is of all end-user's charging their generated renewable energies is given by

$$
\begin{gathered}
C_{R E S}=\sum C_{i} \\
(i=\text { Wind or PV or fuel cell or Bio mass, etc. })
\end{gathered}
$$

where, $C_{\text {wind }}=M_{\text {wind }} \cdot N$ is the cost of wind energy generation, $C_{P V}=M_{P V} \cdot S_{P V}$ is the cost of PV energy generation, $M_{\text {wind }}, M_{P V}$ is the maintenance cost of the relevant equipment per day, $N$ is the total number of wind turbine generators, and SPV is the total area of solar power generating equipment.

The income $B_{\text {grid }}$ represents a function of the RTP tariff and selling the energy from the user's own energy storage facilities to the grid. Therefore, the optimized EMS solution of Equations (3)-(5) adopted the EI framework, and considered the RTP influence based on the demand-supply balance and energy market data with the involvement of renewable energy sources, which is possible in EI and FREEDM architecture.

\section{Benefits and Challenges in Energy Internet Implementation}

The benefits of EI and the hurdles in its practical implementation are discussed in this section.

\subsection{Benefits of EI Implementation}

\section{- Customer Satisfaction}

The implementation of EI results in customer satisfaction, because of economic savings in electricity bills, less maintenance, and smart metering. Also, consumers can communicate directly with the power supply company, which results in flexibility in utilizing power, and they can even sell the excess and act as one of the participants in country development [65]. Thus, the concept of EI provides customer-driven access, which ultimately leads to satisfied customers.

- Development of a new business model

Because of the flexibility introduced in power exchanges with the concept of EI, a new business model is developed. A new trend is established in the world because of small-scale industries showing an interest in this business [66]. Multiple power producers, known as power players, are entering the 
new business model. This creates a more competitive environment, which in turn leads to economic electricity access to consumers.

- Increased utilization of resources

The energy crisis is an essential issue in the world. The EI system will raise the use of renewable energy resources, such as solar, wind, natural gas, tidal, and hydel, which are abundantly available. The EI system integrates all of the RERs at one point, for improved consumer satisfaction.

- Improved system reliability

The reliability of the power system is improved by the frequent system monitoring in EI. The stability is increased because of the balancing of variable loads. Disturbances such as faults and unnecessary breakdowns are reduced, and thus the power system's reliability is improved.

- Increased energy efficiency

EI consists of smart equipment systems, which result in a power-loss reduction. The faster information and communication, planning, and energy telemetry technologies used in EI make the system efficient [67]. The voltage and frequency fluctuations are reduced by using communication-based techniques. The load demand on the remote power plant is reduced. Transmission losses are reduced, and this leads to an increase in energy efficiency by introducing an EI system.

- Optimized energy management system

The main goal of the EMS system is to develop the management of a power grid by optimizing the demand-response, utility price decrement, and revenue saving by decreasing losses. In the EI architecture, with the plug-and-play sharing of load, DRERs and DESDs will generate local balance in the microgrid by decreasing the overall load consumption on the grid tie node, the central monitor, and control, which will manage the system efficiently and effectively, with plenty of advanced EMS techniques based on the real-time pricing environment, as shown in the literature [68].

- $\quad$ Reduced residential consumption

In a constant endeavor to reduce energy usage and have its most effective utilization, EI plays a crucial role. The consumers can manage and control their residential loads in a smart way with the help of EI, and thus reduce energy consumption, which results in energy savings.

- $\quad$ Prediction of power system failures

As EI will collect a large amount of data, the power system failures can be predicted and mitigated with the use of EI. This prediction-based analysis also helps to reduce the system downtime.

\subsection{Challenges in EI implementation}

- $\quad$ Dynamic Pricing

The real-time demand is a variable parameter during off-load and peak load. Thus, to model a service cost based on the customer's demand, a dynamic pricing strategy is required. This is one of the major challenges for the implementation of the EI system. Dynamic pricing can be contrasted with a fixed pricing approach to setting the selling price for a service that does not change.

- $\quad$ bulletInteroperability issues 
The communication standards used by intelligent electronic devices (IEDs) raise the issue of interoperability because of the flexible nature of the standards. Interoperability has a significant influence on the potential economic impact of the EI system, and also the Internet of things. Well-functioning and well-defined system interoperability can encourage innovation and provide efficiencies for EI system developers by increasing the overall economic value of the market.

- Standardization

The development of standards to regulate and control the EI on common grounds is required. Every field, such as power generation, delivery, and control, has their own standards, which are defined by international organizations. Implementing standards is a complex issue because of different vendors with their own legacies, and different countries following their own local standards.

- $\quad$ Stability issues

The transmission system stability issue will become more complex because of EI with a combination of various forms of energy exchange. The power system transfer stability and fault detection for smart-grids connected to EI is yet to be developed.

- Cyber physical security concerns

As the EI system is widely based on information exchanges, it is vulnerable to security threats and the associated cyber physical attacks. The AMI in the EI system consists of smart meters, phasor measurement units (PMUs), which measure and record the energy consumption data as a reference, so that the consumer can make adjustments based on the real-time consumption data. The information about the consumption and appliance usage from smart meters and PMUs might be hacked by the unauthorized parties [69]. Thus, an effective cyber security mechanism is required.

- Scalability

The modern power system of FREEDM attracts vendors and consumers with its flex characteristics. So, it will give rise to a large-scale distributed network. The EI system should maintain a stable performance, even when the number of connected loads change. Its structure must be based on considering the dynamic behavior of the consumers, so that the electrical parameters of the system should not vary as the load increases.

- Congestion

With EI being a wide area network, huge amounts of data are generated from different loads, which lead to a violation of the transmission limits of power lines. This leads to congestion in the transmission network. This is a major challenge for an EI system.

\section{Future Prospects for Energy Internet}

Various future prospects of EI are detailed henceforth.

(1) The heart of EI is ER. In order to have an interoperable and standardized communication framework for ER, the following challenges are to be addressed:

- A standardized information model that addresses the interoperability needs of the power system devices must be developed for ER. Recently, in the literature [70], the authors developed an IEC 61850 standard-based ER model. Building on this work, more analysis on the performance of communication-based ER can be carried out.

- A performance evaluation of the developed information model of ER for different communication technologies, such as LAN, WiFi, and WiMax. 
(2) Power optimization with the help of ER can be explored. This can be achieved by optimizing the energy and information flow path in order to achieve the desired optimal results.

(3) Energy management solution in microgrids can be achieved with effective coordination among ERs. For this purpose, the IEDs of all of the power devices need to be equipped with standard firmware that accommodates suitable EMS data functions.

(4) As the core concept of EI integrates the Internet with the energy transactions, a robust security mechanism is extensively required.

\section{Conclusions}

The impetus towards developing smart cities all over the world, and increased focus towards the use of green and clean energy resources has led to the adoption of smart grid technology. The inclusion of the energy Internet is expected to give a tremendous boost to realizing the aim of the integration of DERs and DESDs with a plug-and-play characteristic. The role of EI in the smart grid paradigm has been covered in this paper. This can bring a good grasp of the advantages of EI in a smart grid paradigm, as well as its related issues in its implementation. A survey of the architecture of EI is carried out in this paper, which will help judiciously opt for the correct architecture for specific usage. Also, in addition to the recent developments of ER, this paper provides guidelines on how the system control will be achieved by different ERs, as well as detailed modelling and designs of the different ERs widely used in EI architecture. Apart from the various benefits of EI, there are numerous challenges in its implementation as well, which are discussed in this paper. Technologies must be well planned in order to leverage their benefits and to prevent the unnecessary loss in the security of electrical networks and communication networks. Finally, future research directions for the energy internet have been proposed, for which it would be beneficial to carry out subsequent research.

Funding: This work was supported in part by Fukushima Prefecture's reconstruction grant 2019.

Conflicts of Interest: The authors declare no conflict of interest.

$\begin{array}{ll}\text { Abbreviations } \\ \text { AMI } & \text { Advanced metering infrastructure } \\ \text { BESS } & \text { Battery energy storage system } \\ \text { CR } & \text { Cognitive radio } \\ \text { DER } & \text { Distributed energy resources } \\ \text { DESDs } & \text { Distributed energy storage devices } \\ \text { DGI } & \text { Distributed grid intelligence } \\ \text { DLC } & \text { Direct load control } \\ \text { DRERs } & \text { Distributed renewable energy resources } \\ \text { EI } & \text { Energy internet } \\ \text { EMS } & \text { Energy management system } \\ \text { ER } & \text { Energy router } \\ \text { FID } & \text { Fault isolation device } \\ \text { FREEDM } & \text { Future renewable electric energy delivery and management } \\ \text { ICT } & \text { Information and communication technologies } \\ \text { IED } & \text { Intelligent electronic devices } \\ \text { IEM } & \text { Intelligent energy management } \\ \text { IFM } & \text { Intelligent fault isolation management } \\ \text { IFM } & \text { Intelligent fault management } \\ \text { IGBT } & \text { Insulated gate bipolar transistor } \\ \text { IOE } & \text { Internet of energy } \\ \text { IoT } & \text { Internet of things } \\ \end{array}$




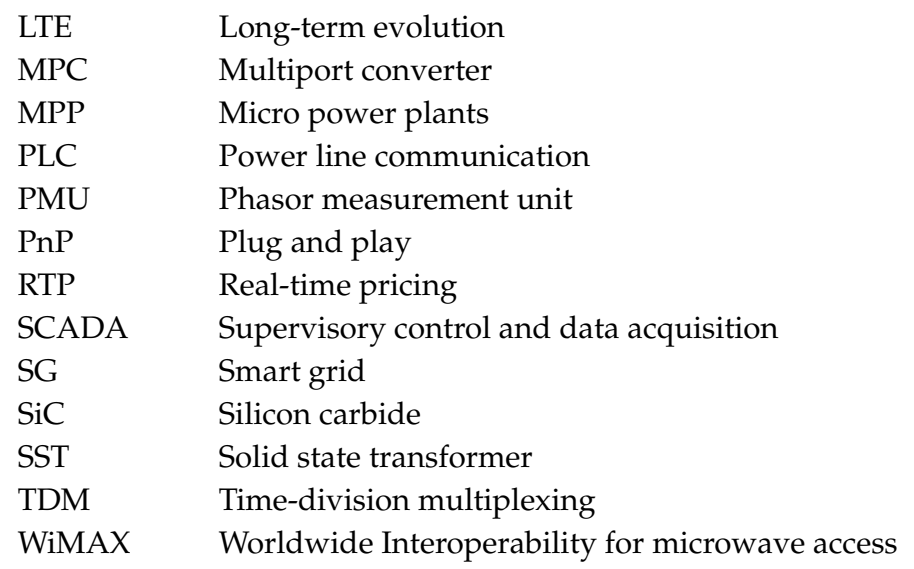

\section{References}

1. Fu, H.; Zhang, X.P. Market Equilibrium in Active Distribution System with $\mu$ VPPs: A Coevolutionary Approach. IEEE Access 2017, 5, 8194-8204. [CrossRef]

2. Jiang, H.; Wang, K.; Wang, Y.; Gao, M.; Zhang, Y. Energy big data: A survey. IEEE Access 2016, 4, $3844-3861$. [CrossRef]

3. Yan, Y.; Qian, Y.; Sharif, H.; Tipper, D. A survey on smart grid communication infrastructures: Motivations, requirements and challenges. IEEE Commun. Surv. Tutor. 2013, 15, 5-20. [CrossRef]

4. Sabbah, A.I.; El-Mougy, A.; Ibnkahla, M. A survey of networking challenges and routing protocols in smart grids. IEEE Trans. Ind. Inform. 2014, 10, 210-221. [CrossRef]

5. Albano, M.; Ferreira, L.L.; Pinho, L.M. Convergence of smart grid ICT architectures for the last mile. IEEE Trans. Ind. Inform. 2015, 11, 187-197. [CrossRef]

6. Aftab, M.A.; Hussain, S.S.; Kumar, V.; Ustun, T.S.; Ali, I. IEC 61850 Communication Assisted Synchronization Strategy for Microgrids. In Proceedings of the 2018 IEEE 13th International Conference on Industrial and Information Systems (ICIIS), Rupnagar, India, 1-2 December 2018.

7. Ali, I.; Hussain, S.S. Communication Design for Energy Management Automation in Microgrid. IEEE Trans. Smart Grid 2018, 9, 2055-2064. [CrossRef]

8. Nadeem, F.; Aftab, M.A.; Hussain, S.S.; Ali, I.; Tiwari, P.K.; Goswami, A.K.; Ustun, T.S. Virtual Power Plant Management in Smart Grids with XMPP Based IEC 61850 Communication. Energies 2019, 12, 2398. [CrossRef]

9. Nadeem, F.; Hussain, S.S.; Tiwari, P.K.; Goswami, A.K.; Ustun, T.S. Comparative Review of Energy Storage Systems, Their Roles, and Impacts on Future Power Systems. IEEE Access 2019, 7, 4555-4585. [CrossRef]

10. Javed, K.; Ashfaq, H.; Singh, R.; Hussain, S.S.; Ustun, T.S. Design and Performance Analysis of a Stand-alone PV System with Hybrid Energy Storage for Rural India. Electronics 2019, 8, 952. [CrossRef]

11. Ustun, T.S.; Hussain, S.S.; Kikusato, H. IEC 61850-Based Communication Modeling of EV Charge-Discharge Management for Maximum PV Generation. IEEE Access 2019, 7, 4219-4231. [CrossRef]

12. Hussain, S.M.S.; Ali, I.; Ustun, T.S.; Aftab, M.A. IEC 61850 and XMPP Communication Based Energy Management in Microgrids Considering Electric Vehicles. IEEE Access 2018, 6, 35657-35668.

13. Asif, A.A.; Singh, R. Further Cost Reduction of Battery Manufacturing. Batteries 2017, 3, 17. [CrossRef]

14. Rifkin, J. Third Industrial Revolution: How Lateral Power Is Transforming Energy, the Economy, and the World. Available online: https:/www.questia.com/library/journal/1G1-357591508/rifkin-j-2011-the-thirdindustrial-revolution (accessed on 15 September 2019).

15. Collier, S.E. The Emerging Enernet: Convergence of the Smart Grid with the Internet of Things. In Proceedings of the 2015 IEEE Rural Electric Power Conference, Asheville, NC, USA, 19-21 April 2015.

16. Keshtkar, A.; Arzanpour, S.; Keshtkar, F. Adaptive residential demand-side management using rule-based techniques in smart grid environments. Energy Build. 2016, 133, 281-294. [CrossRef]

17. Rifkin, J. The Zero Marginal Cost Society; St. Martin's Griffin: New York, USA, 2015.

18. Raghavan, B.; Ma, J. The energy and emergy of the internet. In Proceedings of the 10th ACM Workshop on Programming Languages and Analysis for Security_PLAS'15, Cambridge, MA, USA, 14-15 November 2011. 
19. Wang, K.; Yu, J.; Yu, Y.; Qian, Y.; Zeng, D.; Guo, S.; Xiang, Y.; Wu, J. A Survey on Energy Internet: Architecture, Approach, and Emerging Technologies. IEEE Syst. J. 2017, 12, 2403-2416. [CrossRef]

20. Liu, W.; Zheng, T.; Sun, Z.; Chen, L.; Li, L.; Mei, S. Hierarchical Energy Management for Economic Operation of Micro Energy Internet Systems. In Proceedings of the 2017 36th Chinese Control Conference (CCC), Dalian, China, 26-28 July 2017.

21. Wang, K.; Hu, X.; Li, H.; Li, P.; Zeng, D.; Guo, S. A Survey on Energy Internet Communications for Sustainability. IEEE Trans. Sustain. Comput. 2017, 2, 231-254. [CrossRef]

22. Huang, A.Q.; Crow, M.L.; Heydt, G.T.; Zheng, J.P.; Dale, S.J. The Future Renewable Electric Energy Delivery and Management (FREEDM) System: The Energy Internet. Proc. IEEE 2011, 99, 133-148. [CrossRef]

23. Lin, C.-C.; Deng, D.-J.; Liu, W.-Y.; Chen, L.N. Peak Load Shifting in the Internet of Energy with Energy Trading among End-users. IEEE Access 2017, 5, 1. [CrossRef]

24. Cao, J.; Yang, M. Energy internet-Towards smart grid 2.0. In Proceedings of the 2013 Fourth International Conference on Networking and Distributed Computing, Los Angeles, CA, USA, 21-24 December 2013.

25. Jo, M.; Ejaz, W.; Naeem, M.; Shahid, A.; Anpalagan, A. Efficient Energy Management for the Internet of Things in Smart Cities. IEEE Commun. Mag. 2017, 55, 84-91.

26. Tsoukalas, L.; Gao, R. From smart grids to an energy internet: Assumptions, architectures and requirements. In Proceedings of the 2008 Third International Conference on Electric Utility Deregulation and Restructuring and Power Technologies, Nanjing, China, 6-9 April 2008.

27. Asif, A.A.; Venayagamoorthy, G.K.; Singh, R. Ultra-low cost and solar storm secured local DC electricity to address climate change challenges for all economies. In Proceedings of the 2016 Clemson University Power Systems Conference (PSC), Clemson, SC, USA, 8-11 March 2016.

28. Lu, X.; Wang, W.; Ma, J. An Empirical Study of Communication Infrastructures Towards the Smart Grid: Design, Implementation, and Evaluation. IEEE Trans. Smart Grid 2013, 4, 170-183. [CrossRef]

29. Shen, Z.; Liu, Z.; Baran, M. Power management strategies for The Green Hub. In Proceedings of the 2012 IEEE Power and Energy Society General Meeting, San Diego, CA, USA, 22-26 July 2012.

30. FREEDM Systems Center. Available online: www.freedm.ncsu.edu (accessed on 15 September 2019).

31. Dong, Y.; Cai, Z.; Yu, M.; Sturer, M. Modeling and simulation of the communication networks in Smart grid. In Proceedings of the 2011 IEEE International Conference on Systems, Man, and Cybernetics, Anchorage, AK, USA, 9-12 October 2011.

32. Tatcho, P.; Jiang, Y.; Li, H. A novel line section protection for the FREEDM system based on the solid state transformer. In Proceedings of the 2011 IEEE Power and Energy Society General Meeting, Detroit, MI, USA, USA, 24-28 July 2011.

33. Davies, R. Hydro one's smart meter initiative paves way for defining the smart grid of the future. In Proceedings of the 2009 IEEE Power \& Energy Society General Meeting, Calgary, AB, Canada, 26-30 July 2009.

34. Yang, C.-W.; Yan, J.; Vyatkin, V. Towards implementation of Plug-and-Play and distributed HMI for the FREEDM system with IEC 61499. In Proceedings of the IECON 2013-39th Annual Conference of the IEEE Industrial Electronics Society, Vienna, Austria, 10-13 November 2013.

35. Cheng, X.; Cao, R.; Yang, L. Relay-Aided Amplify-and-Forward Powerline Communications. IEEE Trans. Smart Grid 2013, 4, 265-272. [CrossRef]

36. Zhang, Q.; Sun, Y.; Cui, Z. Application and analysis of ZigBee technology for Smart Grid. In Proceedings of the 2010 International Conference on Computer and Information Application, Tianjin, China, 3-5 December 2010.

37. Aalamifar, F.; Lampe, L. Optimized WiMAX Profile Configuration for Smart Grid Communications. IEEE Trans. Smart Grid 2016, 8, 2723-2732. [CrossRef]

38. Yu, R.; Zhang, C.; Zhang, X.; Zhou, L.; Yang, K. Hybrid spectrum access in cognitive-radio-based smart-grid communications systems. IEEE Syst. J. 2014, 8, 577-587. [CrossRef]

39. Xu, Y.; Fischione, C. Real-time scheduling in LTE for smart grids. In Proceedings of the 20125 th International Symposium on Communications, Control and Signal Processing, Rome, Italy, 2-4 May 2012.

40. Kushiro, N.; Suzuki, S.; Nakata, M.; Takahara, H.; Inoue, M. Integrated residential gateway controller for home energy management system. IEEE Trans. Consum. Electron. 2003, 49, 629-636. [CrossRef] 
41. Bhattacharya, S.; Zhao, T.; Wang, G.; Dutta, S.; Baek, S.; Du, Y.; Parkhideh, B.; Zhou, X.; Huang, A.Q. Design and development of Generation-I silicon based Solid State Transformer. In Proceedings of the 2010 Twenty-Fifth Annual IEEE Applied Power Electronics Conference and Exposition (APEC), Palm Springs, CA, USA, 21-25 February 2010.

42. Wang, L.; Zhang, D.; Wang, Y.; Liu, H. High-frequency solid-state transformer power conversion technologies for energy internet. In Proceedings of the 2017 IEEE 3rd International Future Energy Electronics Conference and ECCE Asia (IFEEC 2017_ECCE Asia), Kaohsiung, Taiwan, 3-7 June 2017.

43. Mainali, K.; Tripathi, A.; Madhusoodhanan, S.; Kadavelugu, A.; Patel, D.; Hazra, S.; Hatua, K.; Bhattacharya, S. A Transformerless Intelligent Power Substation: A three-phase SST enabled by a 15-kV SiC IGBT. IEEE Power Electron. Mag. 2015, 2, 31-43. [CrossRef]

44. Singh, R.; Asif, A.A. Ultra Large Scale Manufacturing Challenges of Silicon Carbide and Gallium Nitride Based Power Devices and Systems. ECS Trans. 2016, 75, 11-18. [CrossRef]

45. Huang, P.A.Q. Solid State Transformer and FREEDM System Power Management Strategies. NSF FREEDM Systems Center, NC State University. Available online: https://www.freedm.ncsu.edu/wp-content/uploads/ 2016/11/FREEDM-Seminar-Series-4-Power-Management-with-SSTs-by-Alex-Huang.pdf (accessed on 15 September 2019).

46. Crow, M.; McMillin, B.; Wang, W.; Bhattacharyya, S. Intelligent Energy Management of the FREEDM System. In Proceedings of the IEEE PES General Meeting, Providence, RI, USA, 25-29 July 2010.

47. Meng, F.; Akella, R.; Crow, M.L.; McMillin, B. Distributed Grid Intelligence for future microgrid with renewable sources and storage. In Proceedings of the North American Power Symposium 2010, Arlington, TX, USA, 26-28 September 2010.

48. Huang, B.; Li, Y.; Zhang, H.; Sun, Q. Distributed Optimal Co-multi-microgrids Energy Management for Energy Internet. IEEE/CAA J. Autom. Sin. 2016, 3, 357-364.

49. Sun, Q.; Han, R.; Zhang, H.; Zhou, J.; Guerrero, J.M. A Multiagent-Based Consensus Algorithm for Distributed Coordinated Control of Distributed Generators in the Energy Internet. IEEE Trans. Smart Grid 2015, 6, 3006-3019. [CrossRef]

50. Xu, Y.; Zhang, J.; Wang, W.; Juneja, A.; Bhattacharya, S. Energy router: Architectures and functionalities toward Energy Internet. In Proceedings of the 2011 IEEE International Conference on Smart Grid Communications (SmartGridComm), Brussels, Belgium, 17-20 October 2011.

51. Geidl, M.; Koeppel, G.; Favre-Perrod, P.; Klockl, B.; Andersson, G.; Frohlich, K. Energy hubs for the future. IEEE Power Energy Mag. 2007, 5, 24-30. [CrossRef]

52. Guo, H.; Wang, F.; Luo, J.; Zhang, L. Review of energy routers applied for the energy internet integrating renewable energy. In Proceedings of the 2016 IEEE 8th International Power Electronics and Motion Control Conference (IPEMC-ECCE Asia), Hefei, China, 22-26 May 2016.

53. Wu, H.; Zhang, J.; Xing, Y. A Family of Multiport Buck-Boost Converters Based on DC-Link-Inductors (DLIs). IEEE Trans. Power Electron. 2015, 30, 735-746. [CrossRef]

54. Takuno, T.; Koyama, M.; Hikihara, T. In-Home Power Distribution Systems by Circuit Switching and Power Packet Dispatching. In Proceedings of the 2010 First IEEE International Conference on Smart Grid Communications, Gaithersburg, MD, USA, 4-6 October 2010.

55. Schulze, M.; Friedrich, L.; Gautschi, M. Modeling and optimization of renewables: applying the Energy Hub approach. In Proceedings of the 2008 IEEE International Conference on Sustainable Energy Technologies, Singapore, Singapore, 24-27 November 2008.

56. Deng, X. Japan digital power grid project. World Sci. 2013, 7, 8-9.

57. Elma, O.; Selamogullari, U.S. An overview of demand response applications under smart grid concept. In Proceedings of the 2017 4th International Conference on Electrical and Electronic Engineering (ICEEE), Ankara, Turkey, 8-10 April 2017.

58. Bui, N.; Castellani, A.; Casari, P.; Zorzi, M. The internet of energy: A web-enabled smart grid system. IEEE Netw. 2012, 26, 39-45. [CrossRef]

59. Hussain, S.M.S.; Tak, A.; Ustun, T.S.; Ali, I. Communication Modeling of Solar Home System and Smart Meter in Smart Grids. IEEE Access 2018, 6, 16985-16996. [CrossRef]

60. Niyato, D.; Xiao, L.; Wang, P. Machine-to-machine communications for home energy management system in smart grid. IEEE Commun. Mag. 2011, 49, 53-59. [CrossRef] 
61. Ali, I.; Aftab, M.A.; Hussain, S.S.; Gupta, S. Software Defined Networks for Smart Substations in an Active Distribution System. J. Eng. Res. 2019, 7, 1-11.

62. Adapa, R.; Chen, J.; Lee, F.; Breipohl, A. Scheduling direct load control to minimize system operation cost. IEEE Trans. Power Syst. 1995, 10, 1994-2001.

63. Telaretti, E.; Dusonchet, L. Battery storage systems for peak load shaving applications: Part 1: Operating strategy and modification of the power diagram. In Proceedings of the 2016 IEEE 16th International Conference on Environment and Electrical Engineering (EEEIC), Florence, Italy, 7-10 June 2016.

64. Bracco, S.; Delfino, F.; Pampararo, F.; Robba, M.; Rossi, M. A dynamic optimization-based architecture for polygeneration microgrids with tri-generation, renewables, storage systems and electrical vehicles. Energy Convers. Manag. 2015, 96, 511-520. [CrossRef]

65. Rana, M.; Rana, M.M. Architecture of the Internet of Energy Network: An Application to Smart Grid Communications. IEEE Access 2017, 5, 4704-4710. [CrossRef]

66. Yaqoob, I.; Hashem, I.A.T.; Ahmed, A.I.A.; Gani, A.; Guizani, M.; Ahmed, E.; Imran, M. Internet of Things Architecture: Recent Advances, Taxonomy, Requirements, and Open Challenges. IEEE Wirel. Commun. 2017, 24, 10-16. [CrossRef]

67. Chen, Z.-X.; Zhang, Y.-J.; Cai, Z.-X.; Li, L.-C.; Liu, P. Characteristics and technical challenges in energy Internet cyber-physical system. In Proceedings of the 2016 IEEE PES Innovative Smart Grid Technologies Conference Europe (ISGT-Europe), Ljubljana, Slovenia, 9-12 October 2016.

68. Li, Y.; Sun, Z.; Han, L.; Mei, N. Fuzzy Comprehensive Evaluation Method for Energy Management Systems Based on an Internet of Things. IEEE Access 2017, 5, 21312-21322. [CrossRef]

69. Farooq, S.M.; Hussain, S.M.S.; Kiran, S.; Ustun, T.S. Certificate Based Authentication Mechanism for PMU Communication Networks Based on IEC 61850-90-5. Electronics 2018, 7, 370. [CrossRef]

70. Hussain, S.S.M.; Aftab, M.A.; Nadeem, F.; Ali, I.; Ustun, T.S. Optimal Energy Routing in Microgrids with IEC 61850 based Energy Routers. IEEE Trans. Ind. Electroni. 2019, 1. [CrossRef]

(C) 2019 by the authors. Licensee MDPI, Basel, Switzerland. This article is an open access article distributed under the terms and conditions of the Creative Commons Attribution (CC BY) license (http://creativecommons.org/licenses/by/4.0/). 